Whatever the explanation, it may yet turn out to be of importance from a pathogenic and a therapentic standpoint that epileptic manifestations are sometines controlled by Niature's own methods.

REFFRENCES

Sou traitement, Paris, 1929

('rouzon, O.: Le syndrome épilepsie, Paris, 1929

L.'nnox, W. G., and Cobb, S. : Epilepsi, London, 1958

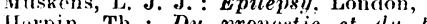

(1)ipilemsie,

3 conwers, W. i. : Epilepsy, London, 1901.

Bain, W. R.: The inheritance of epilepss, Guat. Jomrn, of Mer., 1936, xix, 299

epers. D. F. : A first sturly of inheritance of (1911, xxxriii. 641.

Vienna, xii, 1899

ilson, Kinnier, and

Wolfsohn, J. M.: Organic nervous discase in Trentical twins, Arch. of Neurol. and Psychiat., 1929, xxi, 477.

Thom, 1). A. The Inheritance of Hental Diseases, Baltimore, 1925, p. 71. offorting of epileptics, Boston Med. and Surg. Journ., 1916, claxv, 59G

Pilcz, A. : Die weiteren Lebenschicksale von Kindern welche während dea Bestehens einer mütterlichen Geistes- odrr Nerrenkrankheit geboren worden sind, Jahrb. f: Psychiat. $u$. Meurul., 1928, xlvi, 153.

Dandy, W. E., and Elman, R. : Studies in experimental epilepsy, Bull. Johins Hoplins Hosp., 1925, xxxvi, 40.

12 Brock, S. : The problem of the epiepsies, Internat. ('linics, 19є8, is, 179.

I.ennox, W. G., and cobb, S. : The relation of certain phisicochemical processes to epileptiform seizurcs, Amer. Journ. l'sychiat., 1929, viii, 837.

i Moniz, E., and Lima, A. : Accès épileptiques à asprct Jacksonien homolatéral, déterminés par l'injection d'iodure de sodium clans la carotide interne, C. R. Sec. de Biologie, 1928, xcriii, 1011.

Fay, Temple: Some factors in the mechanical theory of epilepsy, Amer. J"'urn Psychiat., 1929, viii, 783.

Dandy, W. E. : Ventriculography following the injection of air into the cerebral ventricles, Annals of Surgery, 1918, lxviii, 5

Forrster, 0.: Encephalograph

Ronolis, C. E.: Meningitic cpilepsy, Califormia State Jumm. Yed, August, 1921.

1" Moxon, W. : Croonian Lectures, Lancet, 1881, i, 649

" Trousseau, A. : Clinical Medicine, New Syd. Soc., i, 1867

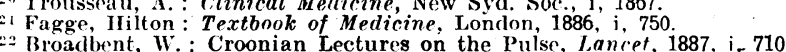

Russell, A. E.: The pathology of epilepsy, Proc. Roy. Soc. Mecl., Iled Sect., December, 1907, p. 71 .

llare, Francis: Mechanism of the paroxysmal neuroses, Allstralasian Med. Giaz., July, 1903.

2.5 Wilson, Kinnier: Modern Problems in Neurolog!, Ionton, 1928, Chan. I.

"ti (Gowers, W. R. : Diseases of the Nervous System, London, 1893, ii, 755 .

Campbell, J. A.; Tissue oxygen-tension with special reference to tetany and convulsions, Journ. of Plysiol., 1925, 1x, 347.

28 I,noir, L. : These de Paris, 1901.

"Ilammond, G. H.: Medical Annual, 1901, p. 241.

Bourneville and Bonnaire : Relation d'une fipiclemis de rougeole observée à l'hospice de Bicêtre dans la section des enfants épileptiques ct idiots, Prog. Méd., 1882, x, 663 .

31 S.glas. J.: De infuence des maladies intercurrentes sur la marche de Tepilepsie, These de raris, 1880

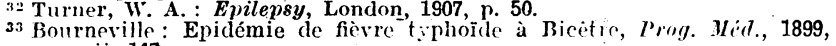
rxvii, 147

\section{TUBERCULOSIS OF THE LARYNX."}

WALTER G. HOWARTH, M.B., B:Ch., F.R.C.S.,

SCRGEON TO THE THROAT DEPARTMENT, ST. THOMAS'S HOSPITAL.

Wrru so large a subject as this it is not easy to know from what side to approach it, and I think that it will probably best serve the purposes of the discussion which is to follow if I make a few remarks from a very general point of view, and let those that follow amplify or criticize some aspect that may particularly appeal to then.

I am afraid that, in spite of the fact that for the past twenty years I have tried to study this disease at St. Thomas's Hospital, the Victoria Park Chest Hospital, and asewhere, I have really nothing to say that is new, and the more cases that one sees the more is one inclined to wonder at the protean manifestations of this disease as far as the larynx is concerned. If one cxamines carefully the larrnx in patients who are suffering from pulmonary tuberculosis, one may say that somewhere about 10 per cent. show abnormality in the larynx. I do not wish to imply. that a definitely recognizable tuberculous lesion is present in all these cases, but that the larynx is not quite normal; it may be that the mucosa is more anaenic than is usual, or there may be a generalized erythema, or possibly some fullness in the interarytenoid region. Do such departures from the normal occurring in a phthisical subject possess more than usual significance, and is there such a thing as

* Rarl in opening a discussion at a joint meeting of the Sections of Oto-Rhino-Laryngology and Tuberculosis at the Annual Mleeting of the a pretuberculous stage of the disease? I believe that many people consider that there is such a stage. Personally $I$ am disinclined to admit this designation, and I would prefer to regard the local anaemia as a nart of a more general one, and the catarrhal laryngitis as a not unusual accompaniment of the chronic cough, while the passage of sputum over the interarytenoid fold is surely sufficient to cause a little local hypertrophy without this being of necessity due to a definite tuberculous infection. At the same tinie, it is raturally advisable to keep a careful watch on such local conditions as they arise, and to make certain that they rield to the appropriate treatment.

What proportion of cases of proved phtlisis exhihit laryngeal symptoms that are definitely tuberulous? Tle auswer to this question. is not very easy, as statistics are. not by any means unanimous on the subject, and, like all statisties, they may be essentially fallacious, as often the information is not given as to what particular class of case is being dealt with. Thus at a large sanatorium (Midhurst) 8 per cent. show definite laryngeal disease, whilst at an institution such as the Victoria Park Chest Hospitai, where the cases are year by year more carefully selected, the preportion may fall as low as 4 per cent. On the other hand, some recent American statistics from a State sanatorium mention 25 per cent. of laryngeal cases. Howerer much statistics vary, it is, I believe, true to say that laryngeal complications of phthisis are certainly less common than they were even twenty-five years ago. Then, the average statistics of many skilled observers in Germany and elsewhere showed considerably more than 30 per cent. This improvement is, I think, indoubtedly due to the fact that the chest disease is recognized earlier and is usually treated most efficiently from the beginning of the disease.

It may be noted that I am assuming that tuberculosis of the larynx is secondary to pulmonaly disease. This is, 1 think, almost universally agreed for the vast majority of cases, even though no definite lesion can be demonstrated in the lungs. There is to my mind, however, one lesion that is cifficult to explain on this assumption, and that is the tiny nodule which may occur on the edge of a rocal cord in ain elderly person, and which may give rise to the suspicion of cancer, but which the microscope proves to be tuberculous in spite of the fact that there was no trace of tuberculosis to be found elsewhere. I can recall at least two cases in which (with the concurrence of distinguished colleagnes) I removed the supposedly cancerous cord with completely successful results, and no further manifestation of tuberculosis over a period of twelve years and seven years respectively.

When the larynx becomes affected in a case of pulmonary tuberculosis, how does the infection occur, and what parts are nost commonly involved? In the large majority of cases secretion coughed up from the lungs produces a surface infection of the laryngeal mucosa, and the infecting bacilli can undoubtedly enter apparently intact epithelium, and still more so epithelium damaged by previous disease. When one consider's the amount of sticky sputum that so often hangs about the interarytenoid region and the posterior ends of the vocal cords, it is perhaps surprising that infection does not more of ten take place. Certainly this stagnation of secretion in the region of the posterioi: commissure can be regarded as a very potent source of infection. In this comnexion it is interesting to note that singers and some other voice useis who do not tolerate any accumulation of mucus in the larynx are said to be less susceptible to laryngeal complications. This may be so, but there are, of course, other explanations.

When we allow the possibility of entry of bacilli through intact or abraded epithelium, or through the ducts of racemose glands, it seems perhaps unnecessary to consider the blood stream as the primary vehicle for the subnucous deposit, and it may, indeed, be doubted whether infection ever occurs this way. At the same time, when once tuberculous disease has been established, spread to neighbouring parts of the larynx may undo::3tedly cccur by extension through the lymphatics.

It is, I think, agreed that in the majority of cases the posterior part of the larynx is most commonly affected, and it is here that we are accustomed to look for the earliest signs of disease. We are all familiar with the firm nodular 
infiltration, the feathery outgrowths, the regular coneshaped palisade, or the round frog-spawn-like excrescences that are so often seen in the early stages, but it is well to remember that it is when the situation is unusual that the diagnosis is more difficult, and it would, in my view, be helpful if some of the many careful observers amongst us would tell us of some unusual appearance that experience has taught them to regard as significant. For my own part I have often thought that a curious, gelatinous-like appearance of one vocal cord merited very careful attention, whilst on sereral occasions a diffuse subglottic infiltration, only caught sight of when the cords are widely abducted, has seemed to be the starting point of the laryngeal disease. But the manifestations are so various that one is often forced to say: "I have never seen anything quite like this before, but it must be tubercle."

It is to my mind remarkable how many of the unusual conditions that one sees in the larynx turn out in the end to be tuberculous. It will scarcely be necessary for me to make more than a brief reference to the symptoms of this disease. They are of two types, and these depend on whether it is the interior of the larynx, or whether it is the structures at the entrance to the larynx; that are affected. It may, however, be well to say that as far as the intralaryngeal type is concerned, long before any definite hoarseness may be present, we may notice, or should notice, any slight alteration in the voice, such as tiring very easily, occasional huskiness, or loss of euphony, and any abnormal sensations in the throat or larynx such as a feeling of great dryness, irritation of a tickling or scratching nature, excess of mucus, and tendency continually to clear the throat. Any of these symptoms should, I suggest, call for a careful laryngeal examination, if such is not indeed part of a routine measure. Diagnosis of any laryngeal involvement in an early stago makes the outlook so much more hopeful.

I should like to turn attention to the question of treatment. Each year: it is being more appreciated that the disease, serious though it undoubtedly is, is not really as hopeless as it is so often represented to be, and that indeed a considerable proportion of cases can definitely be cured, particularly if treatment is instituted at an early stage.

This treatment should, of course, be both general and local. The general treatment should, wherever possible, take place in a sanatorium, or under sanatorium conditions, so that every variation in the lung condition and the general health and resistance of the patient may be carefully watched, for upon the skilful care of the pulmonary disease depends the whole outlook of the patient. It has happened before now that the laryngeal condition has been healed but that the patient has succumbed to the pulmonary disease. In mentioning general treatment it would be well to ensure that there are no gross inflammatory conditions of the upper respiratory tract that might keep up irritation and delay the success of other therapcutic measures.

The question of local treatment has undergone many and various changes during the past twenty-five years, and even now constant experiment is taking place with local applications in the hope of checking the disease and mitigating its more distressing symptoms. From this multiplicity of endeavour two landmarks scem to me to stand out pre-eminently as definite advances. The first is the appreciation of the value of absolute vocal rest, and the second is the substitution of the galvano-cautery for other active surgical treatment. I am not quite certain who it was who first thought. of silence as a means of ensuring physiological rest to the diseased larynx, but I know that in this country one of its earliest and most persistent advocates was Sir StClair Thomson, and he must be gratified to find it now regarded as the keystone in the arch of our local treatment.

It is remarkable what extensive lesions heal up under this treatment alone, always provided that the lung condition is favourable and that the patient co-operates to make the silence as absolute as possible. It will be necessary in the majority of cases to ensure that this treatment is carried out for six months or more, and this naturally puts a great strain on the fortitude of the patient. It will often be noted that for the first month or two little or no improvement is shown, and indeed the larynx may look definitely worse; but suddenly it begins to mend, and from that time progress is steady until complete healing has occurred. It is advisable that the larynx should be inspected once a month and the patient informed of the progress and encouraged to continue the vocal rest.

I'he surgical treatment of local lesions, mainly introduced by Heryng and Krause and advocated in this country by Richard Lake, consists mainly in the removal of infiltrated tissues and the curetting of ulcerated areas with the subsequent rubbing in of lactic acid and other mild caustics. These procedures marked $a$ definite advance and many cases were undoubtedly cured by them; but to-day our Heryng curettes; epiglottis shears, and arytenoid punch forceps are seldom used, as their work can be more effectively performed by the galvano-cautery. The value of galvano-caustic puncture in suitable cases is, I am glad to say, gaining greater recognition, and is, as time goes on, likely to supersede all other procedures in the surgical treatment of local lesions. This method, valuable though it undoubtedly is, should not be used indiscriminately, and the cases in which it is proposed to apply it should be most carefully selected, not only with regard to the extent and situation of the local lesion, but also with careful consideration of the lung condition and the general resistance of the patient. In properly selected cases even a few applications at three-weekly or monthly intervals may restore an infiltrated arytenoid to normal or promote the healing of a definite ulcer. The galvano-cautery acts as a powerful counter-irritant, and it is the hyperaemia that is induced and the formation of granulation tissue with the development of new blood vessels that causes revitalization of the tissues and the healing of the tubercle, rather than any actual destruction of diseased tissue that may be achieved.

My experience of the use of direct sunlight is somewhat limited; it is difficult to be certain of it in this country, and $I$ have never used it to the exclusion of other forms of treatment, so that its individual value is difficult to assess. One is certainly struck by the fact that the laryngeal mucosa is extremely sensitive to reflected sunlight, so that the applications and dosage should be under the strictest control. One of my patients was so pleased at sceing his own larynx with one of these cleverly reflecting appliances, designed, I think, by a Frenchman, that he was constantly sumning it, with anything but beneficial results.

Artificial sunlight has been strongly adrocated by Wessely and others, and ingenious machines have been devised for its application. The dosage can be carefully regulated; but the treatment is apt to be a lengthy one, and of the cases that $I$ have seen under treatment in foreign clinics some would probably have been cured more quickly by other methods.

It is commonly supposed that tracheotomy is only justified in this disease when laryngeal obstruction becomes severe, and that it should not be employed for the sole purpose of putting the larynx at rest. I am amongst those who consider that in some cases tracheotomy is not only justifiable but advisable. These cases are few and far between, and are mainly those in which there is an indolent, almost lupoid, infiltration, and where the lung condition is fibroid or inactive. Such cases, slowly progressive under other forms of treatment, may gradually yield to the complete functional rest that tracheotomy ensures.

For the cases that cannot be cured by the measures I have outlined treatment must unfortunately be mainly symptomatic, and it is in this field that experiment and ingenuity may devise methods and applications that may give considerable relief to the symptoms and amelioration of the laryngeal condition.

The chief symptoms that we have to contest are pain and cough. The relief of pain taxes all our resources, and every form of spray and insufflation may be called in to relieve the pain in swallowing that is so inimical to the general nutrition.

It was hoped that nerve-blocking would provide a means of efficiently controlling painful dysphagia, and in some cases it certainly is of value, but on the whole it has in 
my hands proved rather disappointing, and it seems, to fail most often in advanced cases in which one was hoping the most from it.

Cocainization of the spheno-palatine ganglion, as in the Sluder operation for ethmoidal disease, is said to abolish the reflex pain in the ear, but the effects are naturally only transitory.

Cough, which may be due to the local laryngeal condition, is of ten most satisfactorily relieved by the intratracheal injection of oily solutions. A large variety of diugs have naturally been employed, but a 3 per cent. solution of creosote in olive oil will be found to be as 'ffective as any in relieving the irritation that seems to produce the cough.

There is one oily solution for local application that has within recent years been strongly advocated in America, but of which my experience is so limited that I cannot speak with any degree of first-hand knowledge. I refer to chaulmoogra oil. "This appears to have a definitely beneficial effect not only as regards the diminishing of the irritable cough, but it is said also to allay the painful dysphagia very considerably, besides promoting the healing of ulceration in the larynx. The oil is rather a viscous one, and 1 have had it made up with two parts of almond oil so that it can be readily dropped into the larynx from a larrngeal syringe. If even a part of the benefits that are claimed for it can be substantiated after an extended trial it should certainly prove a most valuable addition to the medical side of our treatment.

It is in the later stages of the disease that the symptoms are so distressing, and anything that call give even temporary relief is well worthy of a trial. It is to be hoped that this discussion may reveal methods that are leelpful and so carry us on the way to the attainment of our object.

\section{TUBERCULOSIS OF THE LARYNX." \\ BY}

Sir STCLATR THOMSON, M.D. F.R.C.P., F.R.C.S.

Ox a rough arerage one out of every three patients with active pulmonary tuberculosis suffers from the complication of a larvongeal lesion. In England todat there are 55,000 individuals who require onr knowledve and care to relieve and, if possible, cure them of this condition. Tuberculosis is not the most killing of the diseases we have to combat. Heart disease still heads the list. Pneumonia and bronchitis, togrether, hurry more people to the grave than does tuberculosis. But when we rencmber that tuberculosis attarks inankind chiefly when in the prime of life, that a third of all deaths between 15 and 40 are due to it, and when wo recall the long and weary and expensive passage to the grave it may entail, we must congratulate the officers of these two Sections on taking this opportunity for focusing attention on what is the most serious complication of tuberculosis, next to meningitis.

Much encouragenent lies in the well-established proof that tuberculosis is becoming both less frequent and less virulent. My own impression-which I hope to verifyis that the lessened virulence of the disease is shown by a climinution in the frequency with which the larynx is involved.

Five years ago I published the results of ten years spent in observing 477 cases of larrngeal disease discovered in 2,541 tuberculous patients, all of whom I had examined. ' With your permission I will use these published figures for a few observations, as more extended experience has only served to confirm the conclusions I have already published as regards sex distribution, incidence of the disease, principles of treatment, prospect of cure, and so forth.

(These various points were then elucidated by a lantern demonstration.)

* Rrad at a joint mecting of the Scctions of Oto-Rhino-Tarrngology and Tuberculosis at the Annual Meeting of the British Medicai Association,
The principal conclusions are as follows:

1. Tuberculosis is found in about 18 per cent. of the patients admitted to a sanatorium.

2. It only occurs in 4.8 per cent. of patients in the early stage of pulmonary tuberculosis (Group 1 of the Turban-Gerhardt classification). Hence

3 . The great importance of early diagnosis.

4. The post-mortem room shows that in adranced cases the larynx may be affected in half the patients who die of pulmonary tuberculosis.

5. The presence of a laryngeal complication darkens the prognosis at all stages. If we study their afterhistory, 60 per cent. of patients who left the samatorium with a healthy larynx are alive when only 30 per cent. of those with a diseased larynx are still surviving after the same lapse of time. In other words, amidst laryngeal cases two are dead out of every three when, amidst larynx-free cases, only one has died.

6. No laryngeal case can be looked on as "slight." Its import. is always serious, both as regards length of treatment required and ultimate recovery.

7. Seventy per cent. of only fairly farourable cases are dead.

8. In only too many cases which come under observation the prospect of recovery is so slight that it may be unjustifiable to submit the sufferer to any trying, dangerous, or expensive treatment.

9. On the other hand, a complete repair of the larynx has been obtained in no less than 25 per cent. of "patients with tuberculous laryngitis.

10. Amongst 477 cases 119 cures have bcen obtained by sanatorium treatment, combined with silence, whispers, and the galvano-cautery. To secure both results-and to forestall the development of this serious complication-we only require earlier diagnosis and more prompt sanatorium treatment:

11. When we recall that Morell Mackenzie wrots that "it is not certain that any cases ever 'recover," we may derive much encouragement from the results.

Hippocrates said that no head injury was so slight that it should be neglected, and none so grave but that it might recover. No laryngeal lesion in tuberculosis is so slight as to be neglected; some serious ones may recover; but the majority of adranced cases are hopeless.

In such a kaleidoscopic disease as tuberculosis it is rash to commit oneself to too definite conclusions. In formulating these opinions time has prevented me from inserting many saring clauses and from dwelling on the relation of the laryngeal lesion and the primary focus to the generả infection and to the local and general resistance. REFERFNCE. "Tuberculosis of the Larynx: "Ten Years" Experience in a Sana-
ton Iuin," Medical Research Council, 1927.

\section{PELLAGRA AMONG THE MAIZE-EATING NATIVES OF THE UNION OF SOUTH AFRICA.}

BY

E. H. CLUVER, M.A., M.D., D.P.H., ASSISTANT HEALTH OFHICER FOR THE UNION OF SOUTH AFRICA.

Is spite of the fact that maize, or mealies, forms the chief article of diet of the Bantu population of the Union, often to the exclusion of all else, pellagra outbreaks have been of relatively infrequent occurrence. Only three otitbreaks of any importance are known to have occurred-one in 1906 when some 150 pellagrins were found anong Zulu rebel prisoners; another in 1912-13, in the Pretoria Mental Institution, affecting about 60 native inmates; and the recent outbreak in the Durban prison command, in which a total of 64 cases have been reported to date among the nonEuropean prisoners. In addition to these outbreaks sporadic cases have been reported, amounting to about 50 , mainly from Natal (including Zululand) and the Transkeian native territory of the Cape Province. Only six of these patients were Europeans, the reniainder being Eurafricans, Indians, or Bantus, the last-named greatly preponderating- 